\title{
DISPERSIVE LIQUID-LIQUID MICROEXTRACTION COUPLED WITH MICRO-VOLUME SPECTROPHOTOMETRY FOR DETERMINATION OF TOTAL IODINE IN URINE SAMPLES
}

\author{
MAHMOOD ALI KAYKHAEI $I^{a, b}$, MASSOUD KAYKHAII ${ }^{c}$, \\ MOHAMMAD HASHEMI ${ }^{d}$ AND MONA SARGAZI
}

\author{
${ }^{a}$ Department of Internal Medicine, School of Medicine, Zahedan University of Medical Sciences, Zahedan, Iran. \\ ${ }^{b}$ Genetics of Non-communicable Disease Research Centre, Zahedan University of Medical Science, Zahedan, Iran \\ ${ }^{c}$ Department of Chemistry, Faculty of Sciences, University of Sistan and Baluchestan, Zahedan 98135-674, Iran. \\ ${ }^{d}$ Department of Clinical Biochemistry, Cellular Molecular Research Centre, Zahedan University of Medical Sciences, Zahedan, Iran
}

\begin{abstract}
This work describes a simple photometric determination of iodine concentrations in urine using a dispersive liquid-liquid microextraction method. After digestion of the urine samples with ammonium persulfate, iodide was oxidized with nitrous acid to ICl2- anion at concentrated hydrochloric acid, then Rhodamine $\mathrm{B}$ is added and the ion-pair formed was extracted into a mixture of toluene (extracting phase) and ethanol (dispersive solvent) and measured spectrophotometrically. By means of this sensitive method, iodine concentrations can be determined in very small amount of urine specimens ( $250 \mu \mathrm{L})$. The calibration curve showed good linearity within the range of $100-900 \mu \mathrm{g} . \mathrm{L}^{-1}\left(\mathrm{R}^{2}=0.985\right)$, and the limit of detection for urine was $33.3 \mu \mathrm{g} . \mathrm{L}^{-1}$. The mean recovery of urine were $95.9-101.2 \%$ with RSD of 2.6-6.6\%. The accuracy and precision of the method was evaluated by comparing to the standard Kolthoff-Sandell method. This suggested method affords a number of advantages, such as being simple, rapid, and inexpensive, with low organic solvent consumption, and is remarkably free from interference effects, rendering it an efficient method for the determination of iodine in urine samples in any routine clinical laboratory.
\end{abstract}

Keywords: Urinary iodine; Methods comparison; Dispersive liquid-liquid microextraction.

\section{INTRODUCTION}

Iodine plays an essential role for the human nutrition, being especially necessary for the synthesis of thyroid hormones that regulate the metabolic rate in all cells. Deficiency of this elements, affects an estimated 1.88 billion individuals worldwide, ${ }^{1}$ representing a major public health concern. It is also creating a need for a simple and cost-effective test which can be used particularly in developing countries with less laboratory facilities and expert staffs to monitor urine iodine levels in population groups or individuals accurately. Sandell-Kolthoff (SK) reaction is the most commonly used method for determination of iodine content of biological fluids such as urine and milk and is the official method of the Association of Official Analytical Chemists (AOAC). ${ }^{2}$ It is a very widely used detection method mainly because of its low cost and needs only a simple photometer for measurements. However, it is very time consuming, takes up to 3 days for one assay run and needs at least $20 \mathrm{~mL}$ of the sample. ${ }^{3}$ Other advanced instrumental methods which have been developed for the determination of iodine, including ion-pair reversed phase liquid chromatography coupled to inductively coupled plasma mass spectrometry, ${ }^{4}$ epithermal instrumental neutron activation analysis and radiochemical neutron activation analysis,,${ }^{5,6}$ inductively coupled plasma mass spectrometry $^{7}$ and energy dispersive X-ray fluorescence ${ }^{8}$ possess a number of disadvantages, mainly their very high cost of instruments, maintenance and operation.

If simple SK method could be coupled with some advanced preconcentration techniques, the analytical performance of this spectrophotometry-based technique can be significantly improved ${ }^{9}$ which makes it suitable for routine tests. Therefore, in this study, we developed and validated a simple, rapid, sensitive and cost-effective spectrophotometric methods based on the formation of an ion pair between iodide and Rhodamine $\mathrm{B}(\mathrm{RB})$ as its organic counter ion and chromophore. In this method, after treatment of urine to remove its interferences, iodide is first reacted with highly concentrated hydrochloric acid to form ICl2 - anion. Then RB was added and the ion-pair is extracted by dispersive liquid-liquid microextraction and finally it is spectrophotometrically measured. ${ }^{10}$

\section{EXPERIMENTAL}

\section{Instrument}

A Perkin-Elmer UV/VIS spectrophotometer, model PE-Lambda 25 (MA, USA) was used for measuring the absorbance and recording the spectra. This instrument was equipped with two $10 \mu \mathrm{L}$ microcells purchased from Starna, UK.

Reagents

All reagents were of analytical grade and were purchased from Merck
KgGA (Germany) and used as received. Milli-Q ${ }^{\circledR}$ water (18.3 M' $\left.\Omega . c m\right)$ was used throughout the experiment after filtering through $0.22 \mu \mathrm{m}$ Nylon membrane. Weigh in $1.3081 \mathrm{~g} \mathrm{KI}$ (superior grade) and dissolve the whole amount with $1000 \mathrm{~mL}$ water to obtain $1000 \mathrm{mg} . \mathrm{L}^{-1}$ iodide solution. Working standard solutions were prepared by serial dilutions of this solution prior to analysis. Rhodamine B $(0.02 \mathrm{M})$, sodium nitrite $(0.01 \mathrm{M})$ and arsenic oxide was prepared by mixing $5 \mathrm{~g}$ of $\mathrm{As}_{2} \mathrm{O}_{3}, 12.5 \mathrm{~g}$ of $\mathrm{NaCl}$ and $100 \mathrm{~mL}$ of $5 \mathrm{~N}$ sulphuric acid in a $500 \mathrm{~mL}$ volumetric flask. This mixture was diluted with distilled water to about $250 \mathrm{~mL}$ and heated until all solids dissolved completely. Then, brought to the mark with water. Ceric ammonium sulfate was prepared by dissolving $5 \mathrm{~g}$ of the solid in $2.5 \mathrm{~N}$ sulphuric acid and diluting to $500 \mathrm{~mL}$ with the same acid.

\section{Urine sample}

Urine sample was collected from a healthy female and stored at $-80{ }^{\circ} \mathrm{C}$ and used throughout all experiments. This participant was not using nutritional supplements containing iodine. Before start of the experiments, sample was brought to the room temperature, of which $250 \mu \mathrm{L}$ was transferred to a canonical centrifuge tube. After addition of $1 \mathrm{~mL}$ of $1 \mathrm{M}$ ammonium persulphate, it was heated in a water bath for $60 \mathrm{~min}$ at $95{ }^{\circ} \mathrm{C}$. Then, this solution was brought to room temperature and was extracted by means of DLLME.

Dispersive liquid-liquid microextraction procedure

After digestion of urine samples, a $250 \mu \mathrm{L}$ aliquot of them was taken and $500 \mu \mathrm{L}$ of sodium nitrite $0.01 \mathrm{M}, 500 \mu \mathrm{L}$ of $0.02 \mathrm{M} \mathrm{RB}$ and $2.1 \mathrm{~mL}$ of $\mathrm{HCl}$ $12.08 \mathrm{M}$ was added to them and the solution was brought to $5.0 \mathrm{~mL}$ by addition of distilled water. This solution contains $5 \mathrm{M}$ of $\mathrm{HCl}$ now. Extraction was performed by rapid (1-2 sec) injection of $875 \mu \mathrm{L}$ of a binary mixture consisted of $175 \mu \mathrm{L}$ of toluene (extracting solvent) and $700 \mu \mathrm{L}$ of ethanol (dispersing solvent) at room temperature. After a few seconds, two phases were appeared, which the upper phase contains iodide-RB ion pair. No need for centrifugation. $10 \mu \mathrm{L}$ of this solution was taken and transferred into a spectrophotometer micro-cell for further analysis at $562 \mathrm{~nm}$.

The reaction between released iodide after digestion with ammonium persulphate in nitrous acid media is:

$$
\mathrm{I}^{-}+2 \mathrm{HNO}_{2}+2 \mathrm{H}^{+}+\mathrm{Cl}^{-}{ }_{\text {(excess) }} \rightarrow \mathrm{ICl}_{2}^{-}+2 \mathrm{NO}+2 \mathrm{H}_{2} \mathrm{O}
$$

Then the resulted anion is micro-extracted into toluene as the ion-pair with rhodamine B.

\section{Optimization of microextraction}

To improve the extraction efficiency, experimental parameters which can potentially affect the enrichment performance, should be optimized; of which, the most important are the kind and volume of extraction and dispersive 
solvents and volume of the sample solution. The effect of these parameters on the extraction efficiency was examined as follows. Parameters such as the amount of $\mathrm{RB}, \mathrm{HCl}$ and nitrous acid were not necessary to be optimized, since they are used as excess during the extraction. Toluene was also reported to be the primer solvent as extraction solvent. ${ }^{11}$

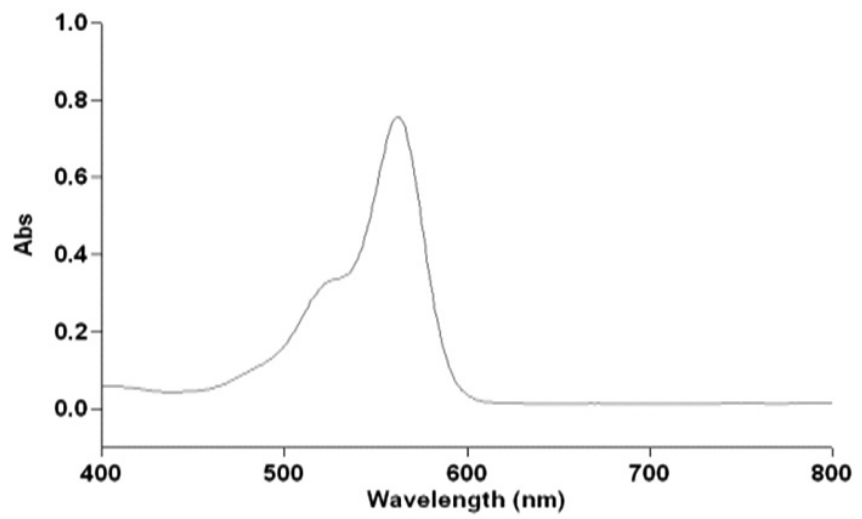

Fig. 1. Absorption spectra for the ion pair formed between $\mathrm{ICl}^{-}$and rhodamine B which shows a maximum absorbance at $562 \mathrm{~nm}$.

\section{Selection of dispersive solvent}

In DLLME, the disperser solvent must be miscible in both extractant solvent (organic phase) and sample solution (aqueous phase). It is necessary that the extractant solvent is dispersed as very fine droplets into the aqueous sample in order to obtain a very high amount of contact area and achieve fast migration of analytes from aqueous sample into the extraction phase. It also has the highest effect on the viscosity of the solution. Common solvents, acetone, acetic acid, methanol and ethanol were selected. The effect of these solvents on the extraction efficiency of DLLME was investigated accurately. Results show that the extraction efficiency was higher using ethanol, hence, this solvent was selected for further experiments (Fig. 2). During this optimization, concentration of the other regents were: $0.1 \mathrm{mM}$ of iodide, $0.01 \mathrm{M}$ of sodium nitrate, $0.02 \mathrm{M}$ of $\mathrm{RB}$ and $5 \mathrm{M}$ of $\mathrm{HCl}$.

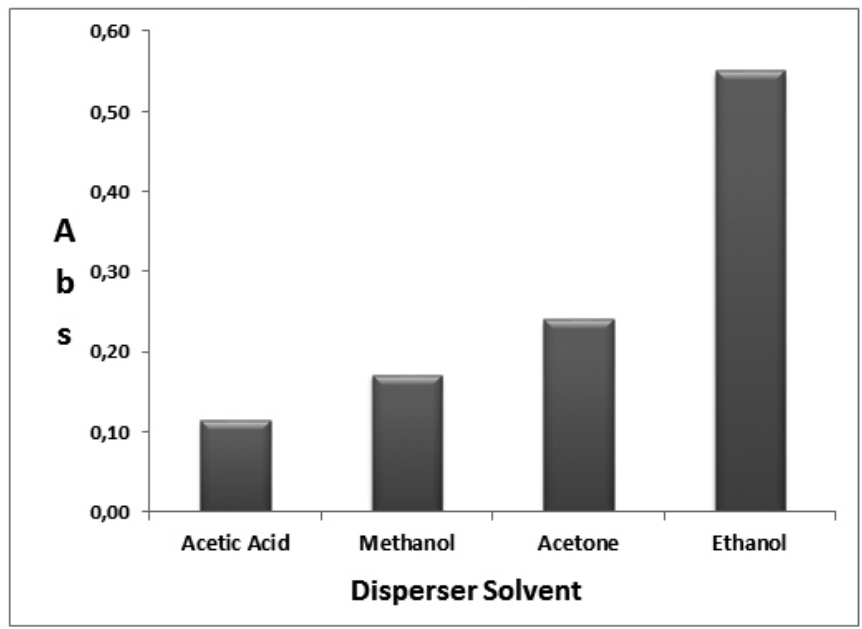

Fig. 2. Effect of type of the disperser solvent on extraction efficiency of the analyte.

\section{Effect of the disperser solvent volume}

The volume of the disperser solvent is one of the important factors to be considered in DLLME. Changing volume of the disperser might lead to the following variations: change in the volume of collected organic phase, size of the droplets and polarity of the aqueous phase. All of these factors are effective on the microextraction efficiency. Hence, it was necessary to evaluat the volume effect of dispersive solvent. Various volumes of ethanol in the range of $500-1,000 \mu \mathrm{L}$ was investigated. For the volumes from 500 to 700 $\mu \mathrm{L}$, the efficiency of extraction increased and then decreased; so $700 \mu \mathrm{L}$ was chosen as the optimized volume for DLLME. Fig. 3 shows the analytical signal obtained as a function of disperser solvent volume. Other conditions were as for previous section.

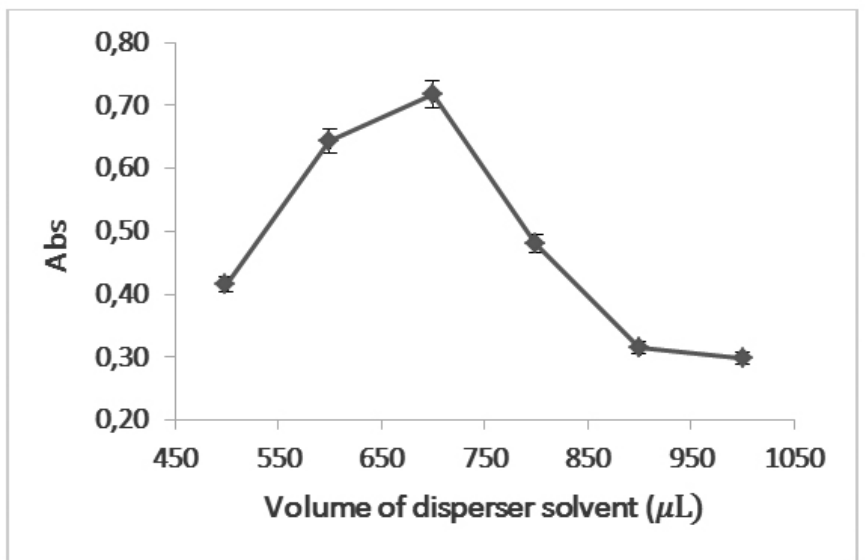

Fig. 3. Effect of volume of the dispersing solvent (ethanol) on extraction efficiency.

Effect of the extracting solvent volume

Volume of the extraction solvent used can affect volume of the organic phase collected after extraction; therefore, extraction solvent volume was studied. Volume of toluene as the extractant solvent was studied in the range of $100-250 \mu \mathrm{L}$. It was observed that at $175 \mu \mathrm{L}$, the signal of the analyte is at its maximum (Fig. 4), so $175 \mu \mathrm{L}$ of toluene was chosen as the volume of extractant.

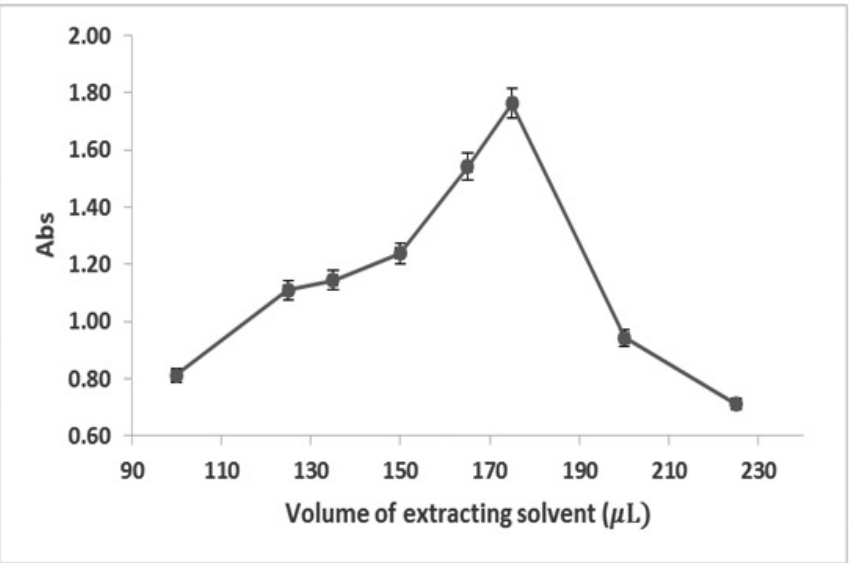

Fig. 4. Effect of volume of the extracting solvent (toluene) on extraction efficiency.

Effect of sample volume

Sample volume can affect disperse ability of binary solution and therefore affect the efficiency of extraction. The effect of sample volume on the extraction efficiency was evaluated by selecting the final solution volume between 3.5 to $6.0 \mathrm{~mL}$ while the iodide content $(0.1 \mathrm{mM})$ and molarity of all other reagents were kept constant. It was found that the best volume samples for DLLME was $5 \mathrm{~mL}$ (Fig. 5). 


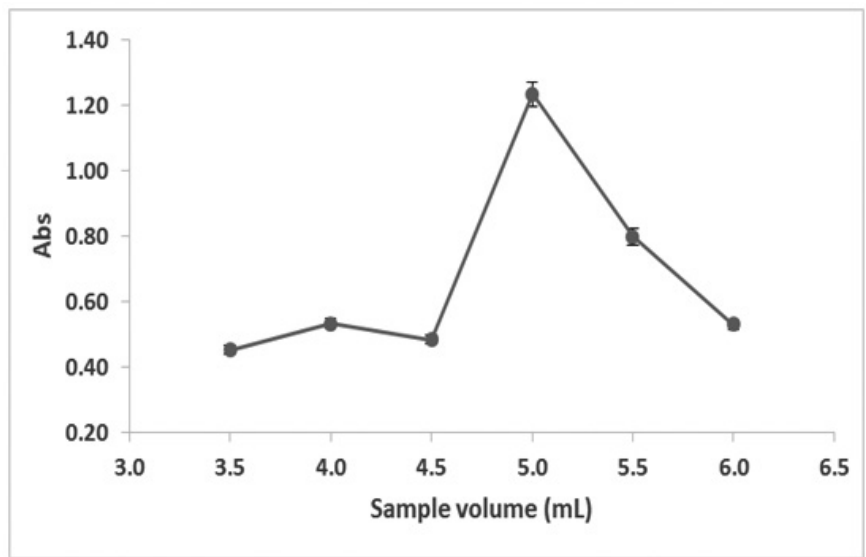

Fig. 5. Effect of sample volume on extraction efficiency.

\section{DISCUSSION}

Analytical figures of merit of the suggested method should be determined, in order to be able to quantitatively analyse the iodine of urine. To do this, the calibration curve for the target analyte was performed using aqueous calibration solutions submitted to the DLLME procedures as described above. Linearity of calibration curve was observed in the range of $100-900 \mu \mathrm{g} \cdot \mathrm{L}^{-1}\left(\mathrm{R}^{2}=0.985\right)$. The limit of detection (LOD) was calculated based on signal-to-noise ratio of $3^{12}$ and found to be $33.3 \mu \mathrm{g} . \mathrm{L}^{-1}$. The precision of the method, expressed as relative standard deviation (RSD), obtained by five consecutive extraction of iodine in a urine sample at the optimized experimental conditions. The enrichment factor was calculated as the ratio between the analyte concentration in the extracting phase $(\mathrm{C})$ and the initial concentration of analyte $\left(\mathrm{C}_{\mathrm{a}}\right)$ within the urine sample measured by SK method, using equation $(1)^{13}$ and was calculated as 55 folds.

$$
\mathrm{EF}=\mathrm{C}_{\text {org }} / \mathrm{C}_{\mathrm{aq}}
$$

Performance of the methods

To evaluate the applicability of the proposed methods, it was applied for the determination of iodine in urine samples by using both normal and standard addition calibration curves. Obtained data were compared to what obtained from SK method. In addition, the same methods were used for determination of urine sample which were spiked in two different levels with iodine, in order to assess effect of different concentration of iodine in its determination. Recoveries were used for assessments which were calculated as the ratio of the response in urine and distilled water samples, spiked with same amount of the analyte. The results are presented in Table 1 . As can be seen, good recoveries were obtained which indicated that our technique can be used for determination of iodine concentration in the range of 100-900 $\mu \mathrm{g} . \mathrm{L}^{-1}$. Also, the Student's t-test and variance ratio F-test for comparison of mean values demonstrated that there is statistically no significant difference between the mean values obtained by three methods at the significance level of 0.05 .

Table 1. The analysis results of iodine of a urine sample and the recovery rates of spiked samples $(n=5)$.

\begin{tabular}{|c|c|c|c|c|}
\hline \multirow{2}{*}{} & \multicolumn{3}{|c|}{ Iodine content $\left(\mu \mathrm{g} . \mathrm{L}^{-1}\right)$ found by using } \\
\cline { 2 - 5 } & $\begin{array}{c}\text { DLLME } \\
(\mathrm{RSD} \%)\end{array}$ & $\begin{array}{c}\text { SK } \\
(\mathrm{RSD} \%)\end{array}$ & $\begin{array}{c}\text { Standard addition } \\
(\mathrm{RSD} \%)\end{array}$ & $80.2(5.4)$ \\
\hline Urine Sample (not spiked) & $80.0(5.4)$ & $80.2(3.1)$ & $460.3(6.3)$ & $1.52(0.41)$ \\
\hline Urine Spiked with $400.0 \mu \mathrm{g} . \mathrm{L}^{-1}$ of I- & $469.6(4.5)$ & $460.3(2.6)$ & $872.3(6.6)$ & $1.37(0.38)$ \\
\hline Urine Spiked with $800.0 \mu \mathrm{g} . \mathrm{L}^{-1}$ of I- & $889.3(3.3)$ & $891.0(4.4)$ & $(0.81)$ \\
\hline
\end{tabular}

\section{CONCLUSION}

In this study, a dispersive liquid-liquid microextraction preconcentration technique for accurate and precise analysis of iodine in urine was developed. The procedure has enough simplicity and sensitivity to be employed for routine analysis of urine samples in any lab. Additional advantages of the developed method are low instrumental costs and easy operation and the whole analysis time of extraction was less than 5 minutes which means many samples can be analysed in a clinical laboratory in each day.

\section{ACKNOWLEDGMENT}

This research was supported by Zahedan University of Medical Sciences.

\section{REFERENCES}

1. T. T. Zava, S. Kapur, D. T. Zava, Anal. Chim. Acta. 764, 64-69, (2013)

2. V. A. Arlington, Official methods of analysis of the association of official analytical chemists. $13^{\text {th }}$ ed, AOAC. 1980; pp. 115.

3. G. A. Kandhro, T. G. Kazi, N. Kazi, Sirajuddin, H. I. Afridi, M. B. Arain, G.A. Baig, A.Q. Shah, S. Khan, N.F. Kolachi, S.K. Wadhwa, F. Shah, Russ. J. Electrochem. 47, 1355-1362, (2011)

4. C. Han, J. Sun, H. Cheng, Z. Xu, Anal. Methods. 6, 5369-5375, (2014)

5. M. Dermeli, Z. Slejkovec, A. R. Byrne, P. Stegnar, S. Hojker, M. Porenta, G. Sestakov, Analyst. 117, 443-446, (1992)

6. M. M. Mason, V. L. Spate, J. S. Morris, S. Chikos, C. K. Baskett, T. P. Cheng, C. L. Reams, L. O. Lemarchand, B. E. Henderson, L. N. Kolonel, Radioanal. Nucl. Chem. 195, 57-65, (1995)

7. P. Allain, Y. Mauras, C. Douge, L. Jaunault, T. Delaporte, C. Beaugrand, Analyst. 115, 813-815, (1990)

8. K. Mwaura, D. G. S. Narayana, A. M. Kinyua, J. Trace Elem. Electrolytes Health Dis. 8, 115-117, (1994)
9. U. Divrikli, M. Soylak, M. Dogan, Chem. Anal-Warsaw. 45, 257-264, (2000)

10. M. Kaykhaii, M. Sargazi, Spectrochim. Acta A. 121, 173-179, (2014)

11. M. A. AL-Hajjaji, Anal. Chim. Acta. 197, 281-284, (1987)

12. H. Yahyavi, M. Kaykhaii, M. Hashemi, RSC. Adv. 6, 2361-2367, (2016)

13. M. R. Rezaei Kahkha, M. Kaykhaii, J. Chil. Chem. Soc. 60, 2986-2988, (2015) 